\title{
Anomalous Origin of the Left Vertebral Artery from the Aortic Arch
}

\author{
Evan H. Einstein, BA*, Linda H. Song, BA, MSPH, Natalia L. A. Villela, BA, \\ Gregory B. Fasani-Feldberg, BS, Jonathan L. Jacobs, BS, MS, Dolly O. Kim, BA, \\ Akshay Nathawat, BA, Devika Patel, BS, MS, Roger B. Bender, MPH, Daniel F. Peters, MD, FACS \\ Department of Cell Biology and Anatomy, New York Medical College, Valhalla, New York, USA
}

\begin{abstract}
Anatomic anomalies of the aortic arch have implications for clinical practice if their significance is understood. Our case study involves a cadaveric finding of the left vertebral artery originating directly from the aortic arch. Although this anatomical variation has been documented, the prevalence of this anomaly may be generally underestimated. After noting this anomaly, we analyzed $\mathbf{2 7}$ cases and found that four female cadavers had the left vertebral artery originating from the aortic arch rather than the left subclavian artery. With a prevalence rate of $14.8 \%$, it would seem that this anomaly is more significant than previously thought, which could have implications for surgical practice.

Copyright (c) 2016 Science International Corp.
\end{abstract}

\section{Key Words}

Aortic arch variation - Left vertebral artery - Aorta -Variation prevalence

\section{Introduction}

The left vertebral artery (LVA) usually arises from the left subclavian artery medial to the thyrocervical trunk. It then enters the foramen transversarium of $C 6$, passes through the transverse processes of all superior cervical vertebrae, and finally enters the foramen magnum while supplying the brain and spinal cord.

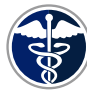

Fax +1 2037853552

E-Mail: aorta@scienceinternational.org

http://aorta.scienceinternational.org

\author{
(c) 2016 AORTA \\ Published by Science International Corp. \\ ISSN 2325-4637 \\ Accessible online at: \\ http://aorta.scienceinternational.org
}

The aortic arch normally gives rise to three vessels: the brachiocephalic trunk (BT), left common carotid artery (LCC), and left subclavian artery (LSA). Variations on this have been observed numerous times and even classified [1]. This report is concerned with the "Adachi TYPE C" variation in which a fourth vessel, an anomalous left vertebral artery, also arises from the aortic arch. The frequency of this variation has generally been reported between $0.68 \%$ and $5.8 \%$ [2-7]. Two additional studies have reported frequencies of $7.41 \%$ and $15.3 \%$ [8, 9]. It is also worth noting that these data indicate that angiography, computed tomography (CT) and MRI studies may underreport the prevalence of this anomaly compared with autopsy-based studies.

\section{Case Presentation}

While performing a cadaveric dissection of the superior mediastinum, an abnormality was noticed at the location of the aortic arch. Upon further examination, it was observed that the aortic arch gave rise to four vessels. The BT, LCC, and LSA were noted to be in their normal locations. A fourth vessel, arising from the aortic arch proximal to the LSA was subsequently found to be the LVA (Figure 1). Further dissection revealed that a branch of the thyrocervical trunk also formed an anastomosis with the aberrant LVA.

\footnotetext{
* Corresponding Author:

Evan Hy Einstein, BA

Department of Cell Biology and Anatomy

New York Medical College

40 Sunshine Cottage Road, Valhalla, New York 10595, USA

Tel.: +1 917860 5569; Fax: +1 914594 4653; E-Mail: evan_einstein@nymc.edu
} 

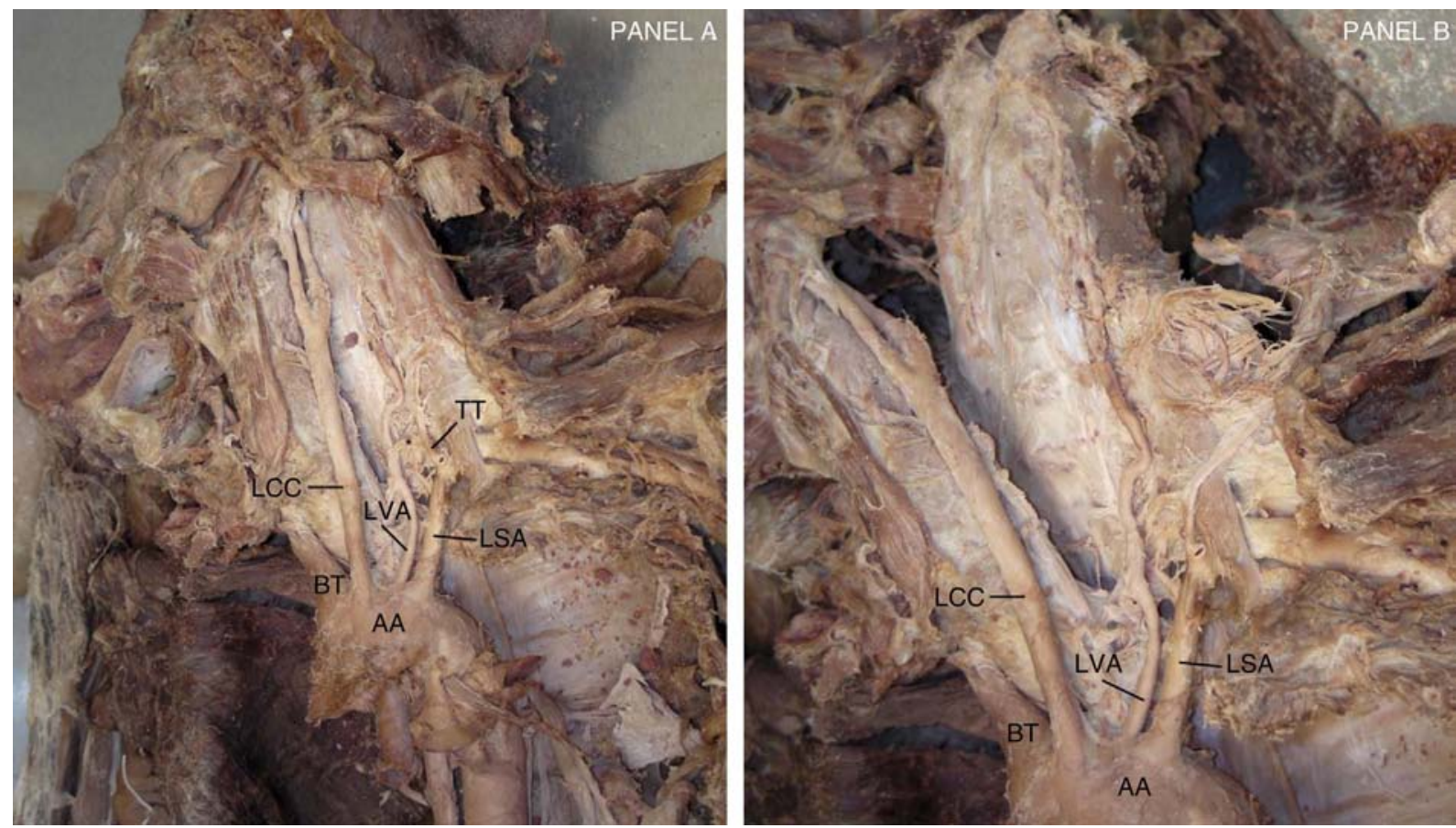

Figure 1. Panel $A$ and Panel B. Views of the superior mediastinum and neck (magnified in Panel B). AA = aortic arch; BT = brachiocephalic trunk; LSA = left subclavian artery; LVA = left vertebral artery; LCC = left common carotid; TT = thyrocervical trunk and anastomoses with LVA (denoted by asterisks).

The LVA itself entered the foramen in the transverse process of $\mathrm{C} 4$, while the anastomotic branch may have supplied the cervical vertebrae below $C 4$.

We subsequently explored the aortic arches of the remaining 26 cadavers in the Gross Anatomy course to document other arch variations. In each case, the manubrium was removed, the superior mediastinum was exposed, and the aortic arch and great vessels were dissected. After examination, it was concluded that 4/27 (14.8\%) cadavers had an aberrant LVA originating from the aortic arch. No other abnormalities were noted. The three additional instances of this variation did not have the additional anastomosis between the LVA and a branch of the thyrocervical trunk. The four cadavers had lifespans of $87,81,89$, and 60 years. Three of the four specimens were Caucasian. The cause of death was cardiopulmonary arrest or otherwise unspecified. None of the cadavers exhibiting this anomaly came with any accompanying history of central nervous system symptoms. Interestingly, all four affected cadavers were female. There were 15 female cadavers in total, corresponding to a $26.7 \%$ prevalence rate of this aberration in females.

\section{Discussion}

Several aortic arch variations have been previously described including examples where the LCC arises from the BT [10] and where both vertebral arteries originate as additional branches of the aortic arch [11]. The variation examined in our case report (LVA origination in the aortic arch) has been previously reported $[12,13]$ at varying frequencies, with most studies reporting a prevalence between $3 \%$ and $8 \%$ [14]. We found a frequency of $14.8 \%(n=27)$. A previous study recorded five out of six of their anomalous cadavers as female [15]. Combined with our findings, this suggests that this anomaly is more prevalent in females.

The development of this variation may involve several factors. Blood vessels develop with the association of growth factors such as vascular endothelial growth factor-A164/165 and placenta growth factor [16]. The latter especially induces the formation of large, stable blood vessels. Release of these factors may be increased, decreased, or temporally varied to allow the LVA to arise from the aortic arch rather than the LSA. 
Embryologically, cervical intersegmental arteries appear longitudinally from the aortic arch as the heart and aorta move caudally. The seventh cervical intersegmental artery gives rise to the LSA, while the dorsal division gives rise to the LVA [17]. The sixth cervical intersegmental artery usually disappears, but in this case it may have remained, allowing blood flow directly from the aortic arch [18]. Because of reduced blood flow through the typical origination of the LVA (i.e., the dorsal division of the seventh cervical intersegmental artery), origination of the LVA from the aortic arch was then possible. Additionally, there was an observed anastomosis between a branch of the thyrocervical trunk and the aberrant LVA in the primary case in this report. This may have occurred due to a portion of the blood flow persisting through the dorsal division of seventh cervical intersegmental artery.

It seems as if this variation may be more common than described in the literature. Our findings support studies reporting higher prevalence rates $[8,9]$ and female predominance. Perhaps the discrepant prevalence rates and the serendipitous nature of these discoveries call for more systematic examination of the aortic arch of each cadaver dissected in laboratories. The aberrant left vertebral is unlikely to have any effect on blood flow, but its presence may well complicate aortic arch surgical and endovascular procedures. Disconnection or compromise of the aberrant vessel could also have cerebral consequences. If the incidence is indeed as high as we suspect, the anomalous vertebral artery is at higher risk in surgical procedures requiring isolation of arch vessels or access to the aortic arch itself. At that point, disruption of cerebral blood flow could be significant.

\section{Acknowledgments}

We are deeply grateful for the anatomic gifts given by the donors. The cadavers are all obtained through a direct donation program. Every donor is honored at a yearly ceremony and convocation of thanks.

\section{Conflict of Interest}

The authors have no conflict of interest relevant to this publication.

\section{Comment on this Article or Ask a Question}

\section{References}

1. Adachi B. Das Arteriensystem der Japaner, 1st Edition. Kyoto: Kenyusha Press; 1928, p. 29-41.

2. Natsis $\mathrm{Kl}$, Tsitouridis IA, Didagelos MV, Fillipidis AA, Vlasis KG, Tsikaras PD. Anatomical variations in the branches of the human aortic arch in 633 angiographies: clinical significance and literature review. Surg Radiol Anat. 2009;31:319-323. DOI: 10.1007/s00276-008-0442-2

3. Sangam MR, Anasuya K. Arch of aorta with bi-carotid trunk, left subclavian artery, and retroesophageal right subclavian artery. Folia Morphol (Warsz). 2010;69:184-186. PMID: 21154291

4. Jakanani GC, Adair W. Frequency of variations in aortic arch anatomy depicted on multidetector CT. Clin Radiol. 2010;65:481-487. DOI: $10.1016 / \mathrm{j}$. crad.2010.02.003

5. Müller $M$, Schmitz BL, Pauls $S$, Schick M, Röhrer S, Kapapa T, et al. Variations of the aortic arch - a study on the most common branching patterns. Acta Radiol. 2011;52:738-742. DOI: 10.1258/ ar.2011.110013
6. Celikyay ZR, Koner AE, Celikyay F, Denız C, Acu $B$. Frequency and imaging findings of variations in human aortic arch anatomy based on multidetector computed tomography data. Clin Imaging. 2013;37: 1011-1019. DOI: 10.1016/j.clinimag.2013. 07.008

7. Karacan A, Türkvatan A, Karacan K. Anatomical variations of aortic arch branching: evaluation with computed tomographic angiography. Cardiol Young. 2014;24:485-493. DOI: 10.1017/ S1047951113000656

8. Bhatia K, Ghabriel MN, Henneberg M. Anatomical variations in the branches of the human aortic arch: a recent study of a South Australian population. Folia Morphol (Warsz). 2005;64:217-223. PMID: 16228958

9. Budhiraja V, Rastogi R, Jain V, Bankwar V, Raghuwanshi S. Anatomical variations in the branching pattern of human aortic arch: A cadaveric study from central India. ISRN Anatomy. 2013;2013:828969. DOI: $10.5402 / 2013 / 828969$

10. Karabulut Ö, Iltimur K, Cudi Tuncer M. Coexisting of aortic arch variation of the left common carotid artery arising from the brachiocephalic trunk and absence of the main branches of the right subclavian artery: a review of the literature. Rom J Morphol Embryol. 2010;51:569-572. PMID: 20809040

11. Goray VB, Joshi AR, Garg A, Merchant S, Yadav B, Maheshwari P. Aortic arch variation: A unique case with anomalous origin of both vertebral arteries as additional branches of the aortic arch distal to left subclavian artery. AJNR Am J Neuroradiol. 2005;26:93-95. PMID: 15661708

12. Panicker HK, Tarnekar A, Dhawane V, Ghosh SK. Anomalous origin of left vertebral artery - embryological basis and applied aspects - a case report. J Anat Soc India. 2002;51:234-235.

13. Kubikova $E$, Osvaldova M, Mizerakova $P$, El Falougy $\mathrm{H}$, Benuska J. A variable origin of the vertebral artery. Bratisl Lek Listy. 2008;109:28-30. PMID: 18447259

14. Singla RK, Sharma T, Sachdeva K. Variable origin of left vertebral artery. Int J Anat Var. 2010;3:97-99. 
15. Nayak SR, Pai MM, Prabhu LV, D'Costa S, Shetty P. Anatomical organization of aortic arch variations in the India: embryological basis and review. JVasc Bras. 2006;5:95-100. DOI: $10.1590 /$ S1677-54492006000200004

16. Nagy JA, Dvorak AM, Dvorak HF. VEGF-A(164/165) and PIGF: roles in angiogenesis and arteriogenesis. Trends Cardiovas Med. 2003;13:169-175. DOI: 10.1016/ S1050-1738(03)00056-2
17. Vorster W, du Plooy PT, Meiring JH. Abnormal origin of internal thoracic and vertebral arteries. Clin Anat. 1998;11:33-37. DOI: 10.1002/(SICI)10982353(1998) 11:1<33::AID-CA5>3.0.CO;2-T

18. Karande NA, Ambiye MV, Khambatta $S$. Anatomical variation of the origin of the left vertebral artery from the arch of the aorta - a case report. Int J Anat Var. 2014;7:96-99.
Cite this article as: Einstein $\mathrm{EH}$, Song LH, Villela NLA, Fasani-Feldberg GB, Jacobs JL, Kim DO, Nathawat A, Patel D, Bender RB, Peters DF. Anomalous Origin of the Left Vertebral Artery from the Aortic Arch. AORTA (Stamford). 2016;4(2): 64-67. DOI: http://dx.doi. org/10.12945/j.aorta.2015.15.022 